\title{
A miR-26a/E2F7 feedback loop contributes to tamoxifen resistance in ER-positive breast cancer
}

\author{
JIAN LIU ${ }^{1 *}$, XIANG LI $^{1 *}$, MENG WANG $^{1}$, GUODONG XIAO $^{1}$, GANGHUA YANG $^{2}$, HUANGZHEN WANG $^{3}$,

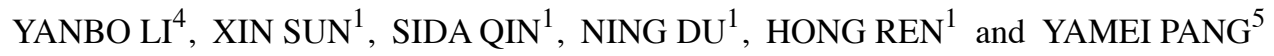 \\ ${ }^{1}$ The Second Department of Thoracic Surgery; ${ }^{2}$ Department of Geriatric Surgery, The First Affiliated Hospital of \\ Xi'an Jiaotong University, Xi'an, Shaanxi 710061; ${ }^{3}$ Department of Surgical Oncology, Baoji Central Hospital, \\ Baoji, Shaanxi 721008; Departments of ${ }^{4}$ Neurology and ${ }^{5}$ Respiratory and Critical Care Medicine, \\ The First Affiliated Hospital of Xi'an Jiaotong University, Xi'an, Shaanxi 710061, P.R. China
}

Received January 29, 2018; Accepted May 31, 2018

DOI: $10.3892 /$ ijo.2018.4492

\begin{abstract}
Tamoxifen (TAM) resistance is a substantial challenge in the treatment of estrogen receptor (ER)-positive breast cancer. Previous studies have revealed an important role of microRNA (miRNA/miR)-26a in TAM resistance in breast cancer. However, the mechanism underlying the regulatory effects of miR-26a on TAM resistance remains to be elucidated. The expression levels of miR-26a in ER-positive breast cancer were detected by reverse transcription-quantitative polymerase chain reaction. E2F transcription factor 7 (E2F7) and MYC proto-oncogene, bHLH transcription factor (MYC) levels were detected by western blotting. The present study demonstrated that miR-26a expression was reduced in ER-positive breast cancer compared with in normal breast tissues, whereas E2F7 expression was significantly elevated. Furthermore, an inverse correlation between miR-26a and E2F7 expression was detected in ER-positive breast cancer. The results indicated that miR-26a directly inhibited E2F7 expression through translational inhibition and indirectly inhibited MYC expression partly via E2F7 repression. E2F7, in turn, decreased miR-26a expression via MYC-induced transcriptional inhibition of miRNAs. Furthermore, transfection with miR-26a mimics increased the expression of its host genes (CTD small phosphatase like and CTD small phosphatase 2), whereas ectopic E2F7 expression abrogated the effects of miR-26a. These findings indicated that miR-26a and E2F7 may form a double-negative feedback loop, resulting in downregulation of miR-26a and upregulation of E2F7 in ER-positive breast cancer. Both miR-26a knockdown and
\end{abstract}

Correspondence to: Dr Yamei Pang, Department of Respiratory and Critical Care Medicine, The First Affiliated Hospital of Xi'an Jiaotong University, 277 Yanta West Road, Xian, Shaanxi 710061, P.R. China E-mail: dr_pangym@163.com

*Contributed equally

Key words: miR-26a, E2F7, MYC, tamoxifen resistance, estrogen receptor, breast cancer
E2F7 overexpression conferred resistance to TAM in MCF-7 cells. Conversely, miR-26a overexpression and E2F7 silencing resensitized MCF-7 resistant cells to TAM. These findings revealed that a feedback loop between miR-26a and E2F7 may promote TAM resistance in ER-positive breast cancer.

\section{Introduction}

Breast cancer is one of the most prevalent female malignancies and the second leading cause of mortality among all cancers in women (1). Approximately $70 \%$ of breast cancers are estrogen receptor (ER)-positive and can be treated with endocrine therapy, such as tamoxifen (TAM) (2). TAM is an anti-estrogen agent, which suppresses ER activity by competitively binding to the ER in ER-positive breast cancer (3). TAM has been used as a first-line adjuvant treatment for patients with ER-positive breast cancer; however, $50 \%$ of patients with ER-positive breast cancer will eventually develop TAM resistance, presenting a huge obstacle to breast cancer treatment (4). Therefore, further understanding of the mechanism underlying TAM resistance may provide novel therapeutic strategies to overcome drug resistance.

MicroRNAs (miRNAs/miRs) function as post-transcriptional regulators by binding to the $3^{\prime}$-untranslated region (3'-UTR) of target mRNAs, thus resulting in translational repression or degradation of the target mRNAs (5). Accumulating evidence has suggested that dysregulation of miRNAs serves an important role in cancer development $(6,7)$. miR-26a is localized in the introns of genes coding for carboxy-terminal domain RNA polymerase II polypeptide A small phosphatase family proteins: CTD small phosphatase like (CTDSPL; miR-26a-1 host gene) and CTD small phosphatase 2 (CTDSP2; miR-26a-2 host gene) $(8,9)$. miR-26a exhibits low expression in breast cancer, and inhibits breast carcinogenesis and metastasis by directly targeting enhancer of zeste 2 polycomb repressive complex 2 subunit (EZH2) and metadherin $(10,11)$. A previous study reported that increasing levels of miR-26a are significantly associated with clinical outcomes of TAM treatment in breast cancer (12). Furthermore, miR-26a is differentially expressed in TAM-resistant breast cancer cells compared with in the parental MCF-7 cell line (13); however, 
the mechanism by which miR-26a regulates TAM resistance is unclear.

The E2F transcription factor (E2F) family can be divided into transcriptional activators $(\mathrm{E} 2 \mathrm{~F} 1-\mathrm{E} 2 \mathrm{~F} 3)$ and repressors (E2F4-E2F8) (14). The E2F family members have an important role in cell cycle control (15). E2F7 overexpression in keratinocytes and osteosarcoma cells results in an accumulation of G1 phase cells and proliferation suppression (15-17). Conversely, E2F7 is able to inhibit apoptosis by repressing E2F1 activity $(16,18)$. Notably, previous studies have revealed that E2F7 is overexpressed in numerous types of cancer, such as squamous cell carcinoma (SCC), endometrial cancer and ovarian cancer $(16,19,20)$. Furthermore, in SCC cells, inhibition of E2F7 increases sensitivity to ultraviolet-induced DNA damage and doxorubicin-induced cytotoxicity by antagonizing E2F1induced apoptosis (16). In addition, E2F7 can directly increase the transcription and activity of the sphingosine kinase-1/sphingosine 1-phosphate axis, resulting in protein kinase $\mathrm{B}$ activation and subsequent doxorubicin resistance (21). Therefore, E2F7 may serve an important role in drug resistance during cancer therapy.

The aim of the study was to explore the role of miR-26a and E2F7 in TAM resistance. The present study demonstrated that miR-26a was inhibited in ER-positive breast cancer, whereas E2F7 was significantly elevated. miR-26a directly inhibited E2F7 expression through translational inhibition and indirectly inhibited MYC proto-oncogene, bHLH transcription factor (MYC) expression partly through suppressing E2F7. E2F7 knockdown, in turn, promoted miR-26a expression by decreasing MYC recruitment to the miR-26a gene promoter. In addition, both miR-26a knockdown and E2F7 overexpression conferred resistance to TAM in breast cancer cells. These findings suggested that miR-26a and E2F7 may form a doublenegative feedback loop that contributes to TAM resistance in ER-positive breast cancer.

\section{Materials and methods}

Cell culture and transfection. Breast cancer cell lines MCF-7, T47D, BT474, SKBR3, MDA-MB-231 and Hs578T, and the normal breast cell line MCF-10A were purchased from American Type Culture Collection (Manassas, VA, USA). The breast cancer cells were cultured in Dulbecco's modified Eagle's Medium (DMEM; Hyclone; GE Healthcare Life Sciences, Logan, UT, USA) supplemented with $10 \%$ fetal bovine serum (FBS; Gibco; Thermo Fisher Scientific, Inc., Waltham, MA, USA) at $37^{\circ} \mathrm{C}$ in a humidified atmosphere containing $5 \% \mathrm{CO}_{2}$. The MCF-10A cell line was cultured in DMEM/F12 (1:1) (Hyclone; GE Healthcare Life Sciences) supplemented with $5 \% \mathrm{FBS}, 10 \mu \mathrm{g} / \mathrm{ml}$ insulin, $20 \mathrm{ng} / \mathrm{ml}$ epidermal growth factor, $100 \mathrm{ng} / \mathrm{ml}$ cholera toxin and $0.5 \mathrm{mg} / \mathrm{ml}$ hydrocortisone at $37^{\circ} \mathrm{C}$ and $5 \% \mathrm{CO}_{2}$. TAM-resistant MCF-7 cells (MCF-7R) were established from MCF-7 cells following a long-term culture with $1 \mu \mathrm{M} 4$-hydroxytamoxifen (Sigma-Aldrich; Merck KGaA, Darmstadt, Germany) as previously described $(22,23)$.

miR-26a mimics, miR-26a inhibitors, E2F7 small interfering RNA (siRNA) and MYC siRNA, and the corresponding negative controls were synthesized by Shanghai GenePharma Co., Ltd. (Shanghai, China). The sequences of the oligonucleotides are provided in Table I. All transfections were conducted using Lipofectamine ${ }^{\circledR} 2000$ (Invitrogen; Thermo
Fisher Scientific, Inc.) according to the manufacturer's protocol. MCF7 and T47D are widely used as experimental models in the study of ER-positive breast cancer; therefore, the subsequent experiments were mainly performed using these two cell lines. Briefly, MCF-7, T47D and MCF-7R cells were plated in 6-well plates at a density of $1 \times 10^{6}$ cells/ well overnight. Subsequently, the cells were transfected with miR-26a mimics or inhibitors, siRNA or corresponding negative controls $(50 \mathrm{nM})$. Total RNA and protein were isolated 48 or $72 \mathrm{~h}$ post-transfection, respectively.

Clinical samples. All clinical samples (35 pairs of ER-positive breast cancer and normal adjacent breast tissues) were obtained from the First Affiliated Hospital of Xi'an Jiaotong University (Xi'an, China) between September 2015 and October 2017. The present study was approved by the Ethics Committee of Xi'an Jiaotong University First Affiliated Hospital and each patient provided written informed consent. The specimens were resected and frozen in liquid nitrogen immediately after surgery. None of the patients received chemotherapy or radiation therapy prior to the study. Patient characteristics are summarized in Table II. Classification of the tumors as ER-positive breast cancer was determined according to the 2009 St. Gallen's Consensus guidelines for ER and progesterone receptor $(\mathrm{PgR})$ markers (24). In addition, to explore the clinical significance of miR-26a and E2F7 in ER-positive breast cancer, RNA-Sequencing and miRNA-Sequencing data from The Cancer Genome Atlas (TCGA) database (http://tcgadata.nci.nih.gov/) were analyzed. A total of 431 ER-positive breast cancer cases with explicit ER, PgR, human epidermal growth factor receptor 2 and menopausal status data were included in the analysis.

Plasmid construction. To construct an E2F7-expressing plasmid (pcDNA3.1-E2F7), a 2,795-bp DNA fragment containing the coding sequence of E2F7 was amplified by PCR from MCF-7 cDNA and cloned into the $X b a \mathrm{I}$ and EcoRI sites of a pcDNA3.1 vector (Invitrogen; Thermo Fisher Scientific, Inc.). The cells were plated in 6 -well plates $\left(1 \times 10^{6}\right.$ cells/well) overnight to ensure $70 \%$ confluence. Then the cells were transfected with the vectors $(4 \mu \mathrm{g} / \mathrm{well})$ using Lipofectamine ${ }^{\circledR} 2000$ (Invitrogen; Thermo Fisher Scientific, Inc.) at $37^{\circ} \mathrm{C}$ for $6 \mathrm{~h}$. The primers used are shown in Table I. The pcDNA3.1 (+) vector was used as a negative control.

Reverse transcription-quantitative polymerase chain reaction $(R T-q P C R)$. Total RNA was isolated using TRIzol ${ }^{\circledR}$ (Invitrogen; Thermo Fisher Scientific, Inc.) according to the manufacturer's protocol.cDNA was synthesized from RNA using a PrimeScript ${ }^{\mathrm{TM}}$ RT Reagent kit (Takara Biotechnology Co., Ltd., Dalian, China) as previously described (25). RT-qPCR was performed using SYBR $^{\circledR}$ Premix Ex Taq ${ }^{\mathrm{TM}}$ II (Tli RNaseH Plus 2X; Takara Biotechnology Co., Ltd.) on a CFX96 ${ }^{\mathrm{TM}}$ Real-Time PCR Detection system (Bio-Rad Laboratories, Inc., Hercules, CA, USA). The thermocycling conditions were as follows: $30 \mathrm{sec}$ at $95^{\circ} \mathrm{C}$, followed by 40 cycles of $5 \mathrm{sec}$ at $95^{\circ} \mathrm{C}, 30 \mathrm{sec}$ at $60^{\circ} \mathrm{C}$ and $72^{\circ} \mathrm{C}$ for $45 \mathrm{sec}$. U6 and $\beta$-actin were used as internal controls for miR-26a and E2F7, respectively. The relative expression levels of target genes were calculated using the $2^{-\Delta \Delta \mathrm{Cq}}$ method (26). The PCR primer sequences are presented in Table I. 
Table I. Oligonucleotides used in the present study.

\begin{tabular}{ll}
\hline Gene name & \multicolumn{1}{c}{ Sequence (5'-3') } \\
\hline Primers for RT-qPCR & \\
E2F7-F & GTCAGCCCTCACTAAACCTAAG \\
E2F7-R & TGCGTTGGATGCTCTTGG \\
MYC-F & TTCGGGTAGTGGAAAACCAG \\
MYC-R & CAGCAGCTCGAATTCTTCC \\
CTDSPL-F & TGCTGAGGGAGGGGAGTGAG \\
CTDSPL-R & GCAGCATGCCACAGGTTGTC \\
CTDSP2-F & ATGTTGGCCAGTCAAGTTCC \\
CTDSP2-R & CTGTCACCTCTGGGAGCAG \\
ACTB-F & CCTTCTACAATGAGCTGCGT \\
ACTB-R & CCTGGATAGCAACGTACATG \\
miR-26a-F & GCCCGCTTCAAGTAATCCAGG \\
miR-26a-R & GTGCAGGGTCCGAGGT \\
U6-F & CCTGCGCAAGGATGAC \\
U6-R & GTGCAGGGTCCGAGGT \\
ChIP-miR-26a1-F & GGAGAGACTGGGAGCGAGTGT \\
ChIP-miR-26a1-R & CAAACTCACAACCTCCCGGT \\
ChIP-miR-26a2-F & CTCCATCTGTGAGCGGCC \\
ChIP-miR-26a2-R & AAAATAGCAAAGCTCCCGACTG \\
Primers for plasmid construction \\
pcDNA3.1-E2F7-F & CTCTAGATAGGAAAGCAGGGATGGA \\
pcDNA3.1-E2F7-R & GGAATTCTCACGATGTGTGCGTTGG \\
Other oligonucleotides & \\
miR-26a mimics & \\
(sense) & UUCAAGUAAUCCAGGAUAGGCU \\
miR-26a mimics & \\
(antisense) & CCUAUCCUGGAUUACUUGAAUU \\
miR-26a inhibitors & AGCCUAUCCUGGAUUACUUGAA \\
E2F7 siRNA & \\
(sense) & \\
E2F7 siRNA & \\
(antisense) & \\
MYC siRNA & \\
\hline
\end{tabular}

ACTB, $\beta$-actin; ChIP, chromatin immunoprecipitation; CTDSP2, CTD small phosphatase 2; CTDSPL, CTD small phosphatase like; E2F7, E2F transcription factor 7; F, forward; miR-26a, microRNA-26a; MYC, MYC proto-oncogene, bHLH transcription factor; R, reverse; RT-qPCR, reverse transcription-quantitative polymerase chain reaction; siRNA, small interfering RNA.

Western blot analysis. Total protein was extracted from cells using radioimmunoprecipitation assay buffer (Thermo Fisher Scientific, Inc.) with proteinase inhibitor (Roche Applied Science, Mannheim, Germany). The protein concentration was measured using a Protein Bicinchoninic Acid Assay kit (Thermo Scientific, Inc.). An equal amount of protein $(20 \mu \mathrm{g})$ mixed with 2X SDS loading buffer was loaded per lane. The proteins were separated by $10 \%$ SDS-PAGE and transferred onto nitrocellulose membranes (Bio-Rad Laboratories, Inc.). The membranes were incubated at room temperature for $2 \mathrm{~h}$ with $5 \%$ nonfat milk to block nonspecific binding.
Table II. Patient characteristics.

\begin{tabular}{lc}
\hline Characteristics & Count \\
\hline Age (mean \pm standard deviation) & $50.4 \pm 10.8$ \\
TNM stage & \\
I-II & 25 \\
III & 10 \\
PgR status & \\
Positive & 27 \\
Negative & 8 \\
HER2 status & \\
Positive & 16 \\
Negative & 19 \\
Histological type & \\
Ductal & 31 \\
Lobular & 4 \\
\hline
\end{tabular}

HER2, human epidermal growth factor receptor 2; PgR, progesterone receptor.

Subsequently, the membranes were incubated for $12 \mathrm{~h}$ at $4^{\circ} \mathrm{C}$ with the following primary antibodies: Anti-MYC $(1: 1,000$; cat. no. sc-764; Santa Cruz Biotechnology, Inc., Dallas, TX, USA) and anti-E2F7 (1:1,000; cat. no. ab56022; Abcam, Cambridge, MA, USA). The membranes were then incubated with horseradish peroxidase-conjugated secondary antibodies (1:5,000; cat. no. sc-2004; Santa Cruz Biotechnology, Inc.) at room temperature for $2 \mathrm{~h}$. Anti- $\beta$-actin antibody $(1: 5,000$; A5441; Sigma-Aldrich, Merck KGaA) was used as a loading control. The protein bands were visualized using an enhanced chemiluminescence substrate (EMD Millipore, Billerica, MA, USA). The results were quantified using ImageJ software (version 1.50b; National Institutes of Health, Bethesda, MD, USA).

MTT assay. A total of $24 \mathrm{~h}$ post-transfection, the cells were seeded in 96 -well plates at a density of $4 \times 10^{3}$ cells/well. Following treatment with or without $1 \mu \mathrm{M} 4$-hydroxytamoxifen for 24, 48, 72 and $96 \mathrm{~h}$, cell viability was detected using the MTT assay. MTT solution $(20 \mu \mathrm{l} ; 5 \mathrm{mg} / \mathrm{ml})$ was added to each well and the cells were incubated at $37^{\circ} \mathrm{C}$ for $4 \mathrm{~h}$. Subsequently, the medium containing MTT solution was discarded, and $150 \mu \mathrm{l}$ dimethyl sulfoxide was added to the wells. The absorbance of each well was measured at $570 \mathrm{~nm}$ using a microplate reader (Bio-Rad Laboratories, Inc.).

Cell cycle analysis. MCF-7 and MCF-7R cells were seeded in the presence of $1 \mu \mathrm{M} 4$-hydroxytamoxifen or ethanol solvent. After $72 \mathrm{~h}$, the cells were trypsinized, washed with PBS and fixed with $70 \%$ ethanol at $4^{\circ} \mathrm{C}$ overnight. The cells were then stained with propidium iodide (Sigma-Aldrich; Merck KGaA) for $30 \mathrm{~min}$ and analyzed by flow cytometry (FACSCalibur; BD Biosciences, Franklin Lakes, NJ, USA) with the ModFit software (Verity Software House, Inc., Topsham, ME, USA).

Luciferase activity assay. The Targetscan database (http://www. targetscan.org/mamm_31/) was used to identify predicted 

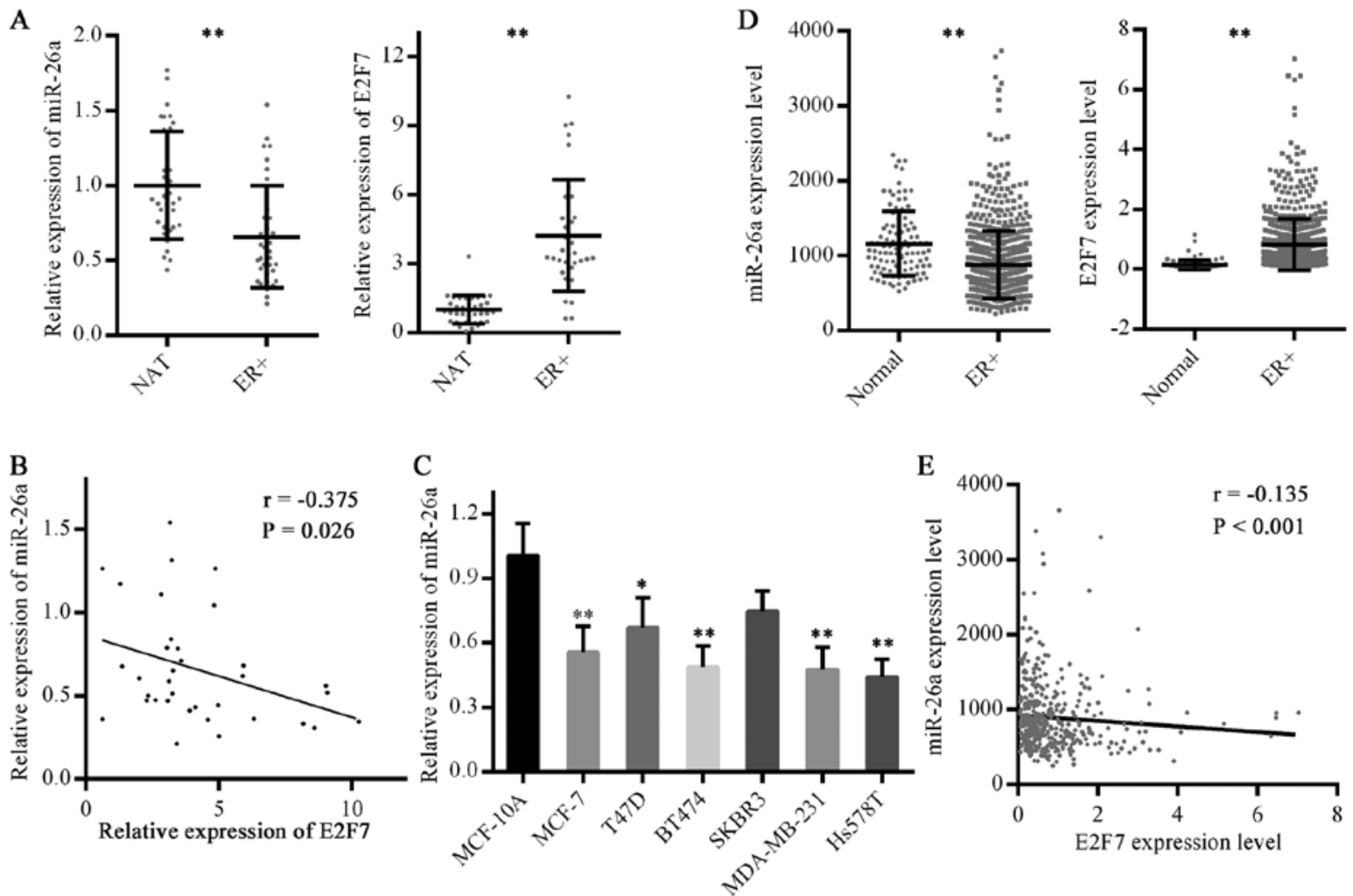

Figure 1. Expression levels of miR-26a and E2F7 in ER-positive breast cancer. (A) miR-26a and E2F7 expression in ER-positive breast cancer was detected by RT-qPCR. NAT, $n=35, E^{+}, n=35 .{ }^{* *} \mathrm{P}<0.01$. (B) Correlation between miR-26a and E2F7 expression in ER-positive breast cancer was analyzed. (C) miR-26a levels in breast cancer cell lines and a normal breast cell line were analyzed by RT-qPCR. Data are presented as the means \pm standard deviation of three independent experiments. ${ }^{*} \mathrm{P}<0.05$ and ${ }^{* * *} \mathrm{P}<0.01$ vs. MCF-10A cells (one-way analysis of variance followed by Dunnett's test). (D) miR-26a expression data in TCGA miRNA-Seq and E2F7 expression data in TCGA RNA-Seq were analyzed. Normal, $n=104$ for miRNA-Seq and $n=113$ for RNA-Seq; ER ${ }^{+}, n=431$. $^{* *} \mathrm{P}<0.01$. (E) Correlation between miR-26a and E2F7 expression in ER-positive breast cancer cases in TCGA database was analyzed. E2F7, E2F transcription factor 7; ER, estrogen receptor; miR-26a, microRNA 26a; NAT, normal adjacent breast tissues; r, correlation coefficient; RT-qPCR, reverse transcription-quantitative polymerase chain reaction; TCGA, The Cancer Genome Atlas.

targets of miR-26a. A fragment of the E2F7 3'-UTR containing two miR-26a-binding sites was cloned into a pGL3-control vector (Promega Corporation, Madison, WI, USA). The seed sequences in the E2F7 3'-UTR complementary to miR-26a were mutated using a QuikChange II Site-Directed Mutagenesis kit (Stratagene; Agilent Technologies GmbH, Waldbronn, Germany). MCF-7 cells were plated in 24-well plates and co-transfected with $100 \mathrm{ng}$ firefly luciferase report vector and 10 ng pRL-TK vector containing Renilla luciferase (Promega Corporation), together with $50 \mathrm{nM}$ miR-26a mimics or negative control mimics. Co-transfection was performed with Lipofectamine ${ }^{\circledR} 2000$ (Invitrogen; Thermo Fisher Scientific, Inc.) at $37^{\circ} \mathrm{C}$ for $6 \mathrm{~h}$. Subsequently, $48 \mathrm{~h}$ post-transfection, the cells were assayed for firefly and Renilla luciferase activities using a Dual-Luciferase Reporter Assay system (Promega Corporation), according to manufacturer's protocol.

Chromatin immunoprecipitation (ChIP). The miR-26a promoter sequence was analyzed using UCSC Genome Browser (http://genome.ucsc.edu). ChIP was performed as previously described $(27,28)$. Briefly, cells were cross-linked with $1 \%$ formaldehyde for $10 \mathrm{~min}$ at $37^{\circ} \mathrm{C}$ and resuspended in lysis buffer on ice for $15 \mathrm{~min}$. Samples were sonicated on ice at a frequency of $20 \mathrm{kHz}$ (on $5 \mathrm{sec}$ and off $12 \mathrm{sec}$ for 13 cycles) to shear chromatin to fragments of 200-1,000 base pairs. The DNA fragments were used in immunoprecipitation with the antibody anti-MYC (cat. no. sc-764; Santa Cruz Biotechnology, Inc.). The primers used for subsequent RT-qPCR are presented in Table I.

Statistical analysis. All statistical analyses were performed using SPSS software (version 20.0; IBM Corp., Armonk, NY, USA). All data are presented as the means \pm standard deviation of at least three independent experiments. The statistical significance of continuous variables was determined using Student's t-test (two-tailed) or Mann-Whitney U test. Multiple group comparisons were analyzed with one-way analysis of variance followed by Dunnett's or least significant difference post hoc tests. For categorical variables, statistical significance was determined using the $\chi^{2}$ test. $\mathrm{P}<0.05$ was considered to indicate a statistically significant difference.

\section{Results}

Expression of miR-26a and E2F7 in ER-positive breast cancer. The present study analyzed miR-26a and E2F7 expression in 35 pairs of ER-positive breast cancer tissues and matched adjacent normal breast tissues using RT-qPCR. The results demonstrated that miR-26a expression was reduced in ER-positive breast cancer compared with in the matched normal breast tissues, whereas E2F7 expression was significantly elevated (Fig. 1A). In addition, E2F7 expression was inversely correlated with miR-26a expression in ER-positive 
Table III. Association of miR-26a and E2F7 expression levels with clinicopathological factors analyzed using The Cancer Genome Atlas datasets.

\begin{tabular}{|c|c|c|c|c|c|c|}
\hline \multirow[b]{2}{*}{ Clinicopathological factor } & \multicolumn{3}{|c|}{ miR-26a level } & \multicolumn{3}{|c|}{ E2F7 level } \\
\hline & Low $(n=215)$ & High $(n=216)$ & P-value & Low $(n=215)$ & High $(n=216)$ & P-value \\
\hline Age (years) & & & 0.290 & & & 0.012 \\
\hline$<60$ & 114 & 103 & & 95 & 122 & \\
\hline$>60$ & 101 & 113 & & 120 & 94 & \\
\hline Tumor size $(\mathrm{cm})$ & & & 0.026 & & & 0.436 \\
\hline$<5$ & 189 & 172 & & 177 & 184 & \\
\hline$>5$ & 26 & 44 & & 38 & 32 & \\
\hline Lymph node metastasis & & & 0.123 & & & 0.965 \\
\hline Negative & 113 & 96 & & 99 & 99 & \\
\hline Positive & 102 & 120 & & 116 & 117 & \\
\hline Distant metastasis & & & 0.623 & & & 0.996 \\
\hline Negative & 214 & 213 & & 213 & 214 & \\
\hline Positive & 1 & 3 & & 2 & 2 & \\
\hline PgR status & & & 0.895 & & & 0.234 \\
\hline Positive & 182 & 181 & & 186 & 177 & \\
\hline Negative & 33 & 35 & & 29 & 39 & \\
\hline HER2 status & & & 0.067 & & & 0.135 \\
\hline Positive & 57 & 41 & & 42 & 56 & \\
\hline Negative & 158 & 175 & & 173 & 160 & \\
\hline Histological type & & & $<0.001$ & & & $<0.001$ \\
\hline Ductal & 183 & 138 & & 136 & 185 & \\
\hline Lobular & 32 & 78 & & 79 & 31 & \\
\hline Menopausal status & & & 0.181 & & & 0.146 \\
\hline Premenopausal & 59 & 47 & & 46 & 60 & \\
\hline Postmenopausal & 156 & 169 & & 169 & 156 & \\
\hline
\end{tabular}

E2F7, E2F transcription factor 7; HER2, human epidermal growth factor receptor 2; miR-26a, microRNA-26a; PgR, progesterone receptor.

breast cancer (Fig. 1B). Subsequently, the present study determined that miR-26a levels in breast cancer cell lines were decreased compared with in the MCF-10A cell line (Fig. 1C). These results suggested that miR-26a may be downregulated in ER-positive breast cancer, whereas E2F7 may be upregulated.

To verify this conclusion, miR-26a and E2F7 expression were evaluated in ER-positive breast cancer cases contained in TCGA) database. Consistent with the RT-qPCR results, miR-26a exhibited reduced expression, whereas E2F7 expression was higher, in ER-positive breast cancer compared with in normal breast tissues (Fig. 1D). In addition, an inverse correlation between miR-26a and E2F7 expression was identified (Fig. 1E). Subsequently, the association of miR-26a and E2F7 expression with clinicopathological factors was analyzed using TCGA data. The results demonstrated that both miR-26a and E2F7 expression levels were associated with histological type; in addition, miR-26a levels were correlated with tumor size and E2F7 levels with age at diagnosis (Table III).

miR-26a inhibits E2F7 and MYC expression. A previous study demonstrated that miR-26a inhibits E2F7 expression by directly binding to its 3'-UTR in acute myeloid leukemia (AML) cells (29). To further investigate whether miR-26a inhibits E2F7 expression in breast cancer cells, the present study introduced miR-26a mimics into MCF-7 and T47D cells. RT-qPCR analysis demonstrated that miR-26a expression was elevated in cells transfected with miR-26a mimics compared with the negative control (Fig. 2A). Furthermore, western blot analysis confirmed that E2F7 protein expression was decreased in the miR-26a mimics groups (Fig. 2B). However, miR-26a overexpression did not decrease E2F7 mRNA expression (Fig. 2C).

To further confirm the targeting of E2F7 by miR-26a, a luciferase activity assay was performed in MCF-7 cells. Using the TargetScan database, two putative binding sites for miR-26a were predicted in the E2F7 mRNA 3'-UTR (Fig. 2D). Luciferase reporter vectors were constructed with the wild-type 3'-UTR of E2F7 (E2F7-Wt), a mutant 3'-UTR of E2F7 at site 1 or site 2 (E2F7-M1 or M2) or a mutant 3'-UTR of E2F7 at both sites (E2F7-DM) (Fig. 2D). As expected, luciferase activity was significantly reduced following transfection with the E2F7-Wt vector. The E2F7-M1 vector slightly abrogated the inhibitory effects of miR-26a; however, this effect was more significant with the E2F7-M2 vector. Notably, E2F7-DM vector completely eradicated the inhibitory effects 
A

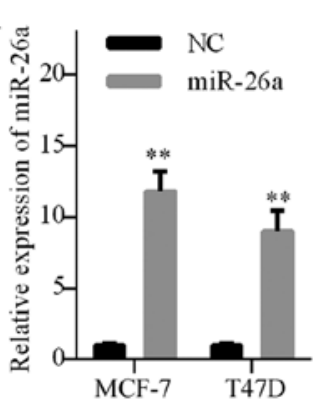

D
B

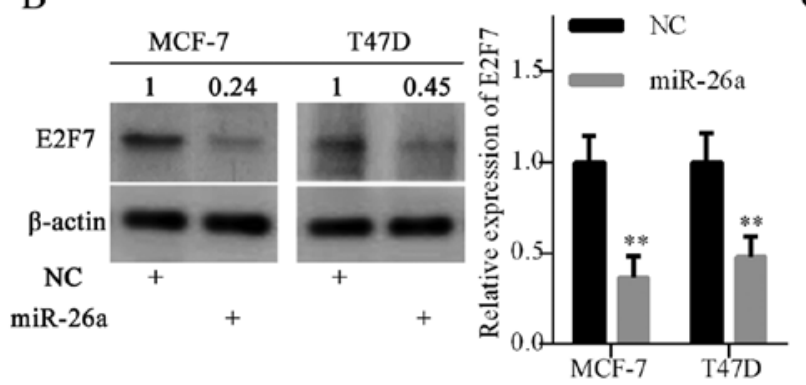

$\mathrm{C}$

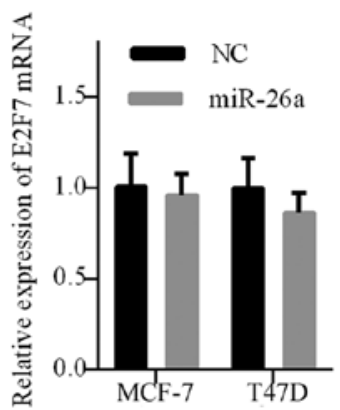

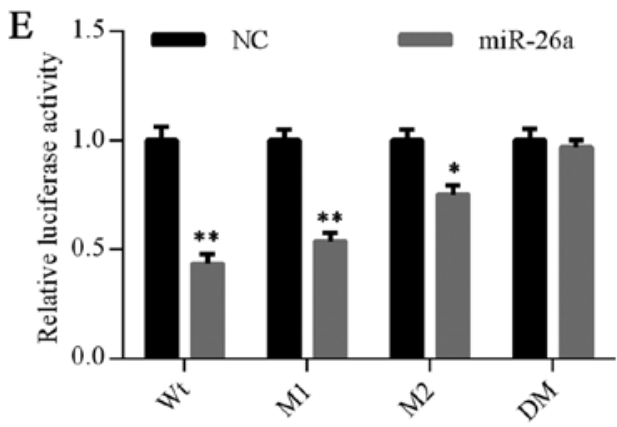

Figure 2. E2F7 is directly inhibited by miR-26a. (A) miR-26a expression in MCF-7 and T47D cells post-transfection with miR-26a mimics was detected by RT-qPCR. (B) E2F7 protein levels in MCF-7 and T47D cells were analyzed by western blotting. (C) E2F7 mRNA levels in MCF-7 and T47D cells were detected by RT-qPCR. (D) Diagram showing the two predicted binding sites in the 3'-UTR of E2F7 mRNA for miR-26a. (E) Validation of direct targeting of E2F7 by miR-26a using a luciferase reporter assay. Data are presented as the means \pm standard deviation of three independent experiments. $\mathrm{P}<0.05$ and ${ }^{* *} \mathrm{P}<0.01$. 3'-UTR, 3'-untranslated region; DM, double mutant; E2F7, E2F transcription factor 7; M, mutant; miR-26a, microRNA 26a; NC, negative control; RT-qPCR, reverse transcription-quantitative polymerase chain reaction; Wt, wild-type.

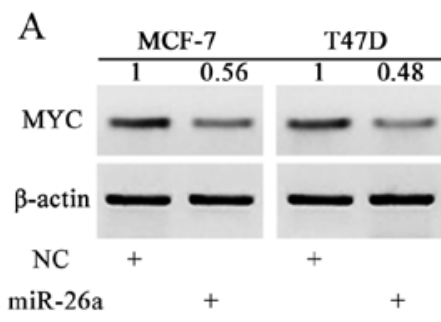

C

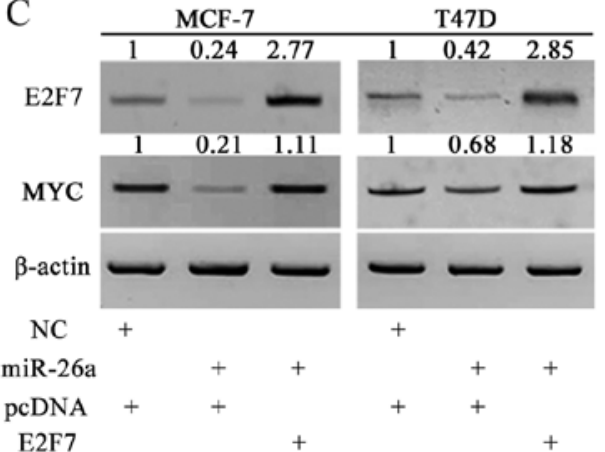

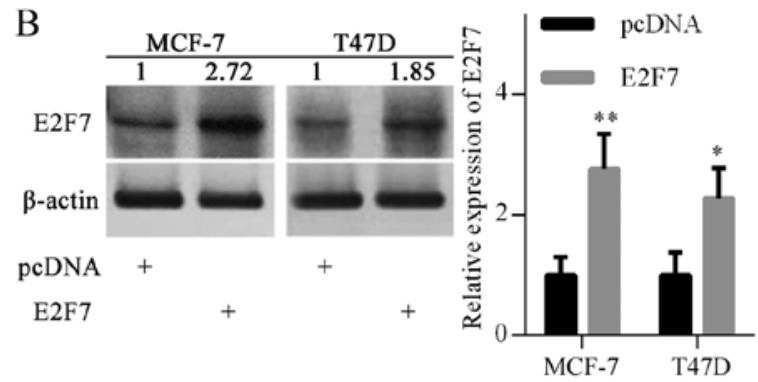
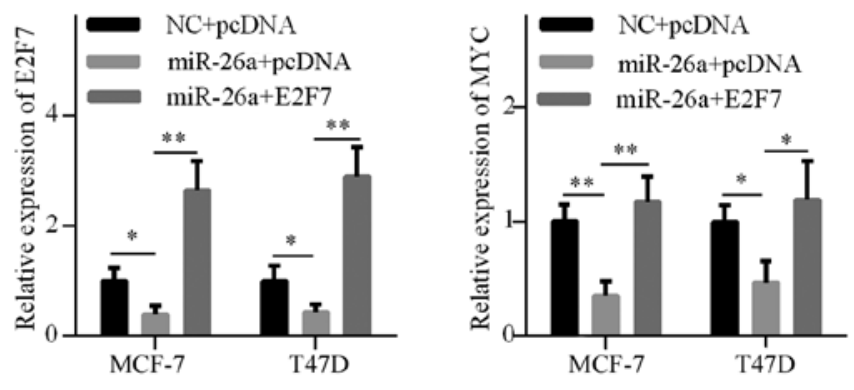

Figure 3. miR-26a inhibits MYC expression via E2F7 repression. (A) MYC expression in MCF-7 and T47D cells following miR-26a mimics transfection was detected by RT-qPCR. (B) MCF-7 and T47D cells were transfected with pcDNA3.1 vector or pcDNA3.1-E2F7. E2F7 expression in MCF-7 and T47D cells was detected by western blotting. (C) MCF-7 and T47D cells were transfected with pcDNA3.1 vector plus NC mimics, pcDNA3.1 vector plus miR-26a mimics, or pcDNA3.1-E2F7 plus miR-26a mimics. E2F7 and MYC expression were detected by western blotting. ${ }^{*} \mathrm{P}<0.05$ and ${ }^{* *} \mathrm{P}<0.01$ (one-way analysis of variance followed by least significant difference test). E2F7, E2F transcription factor 7; miR-26a, microRNA 26a; MYC, MYC proto-oncogene, bHLH transcription factor; NC, negative control; RT-qPCR, reverse transcription-quantitative polymerase chain reaction.

of miR-26a (Fig. 2E). Collectively, these results suggested that miR-26a may inhibit E2F7 expression by directly targeting the 3'-UTR of E2F7 mRNA.
miR-26a overexpression also inhibited MYC protein expression, as shown in Fig. 3A. To investigate the possible mechanism, the pcDNA3.1-E2F7 plasmid was introduced into 
A

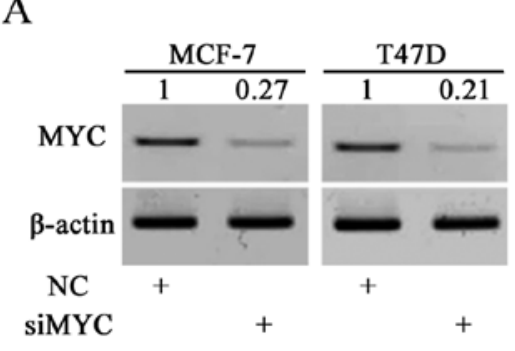

C

C

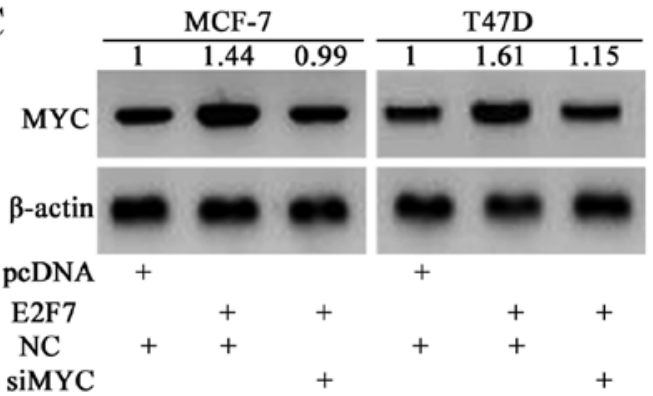

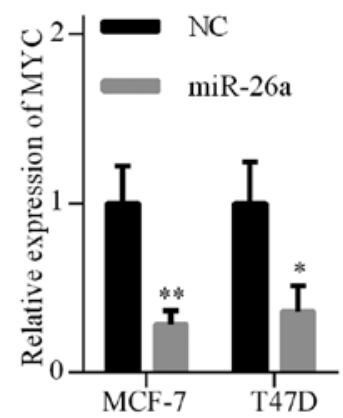

B

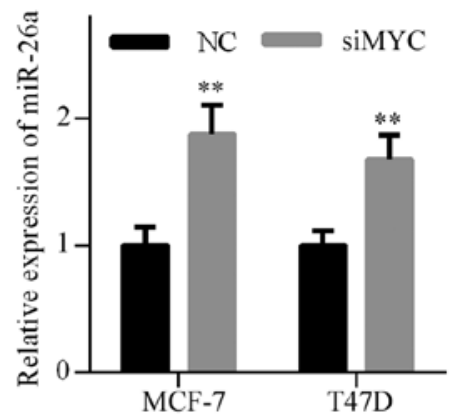

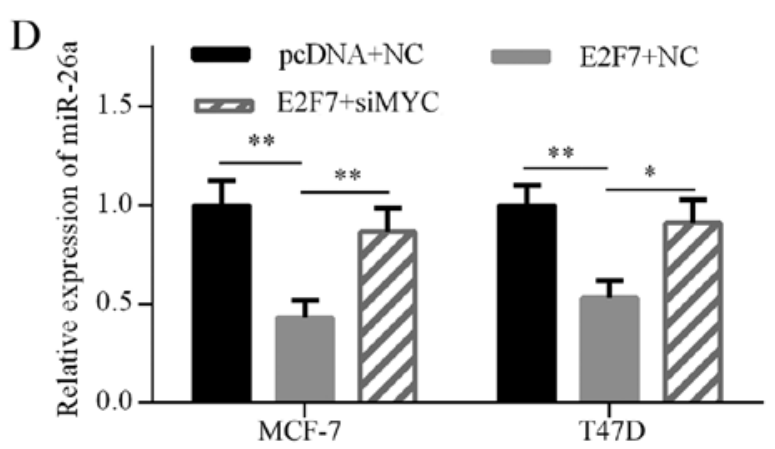

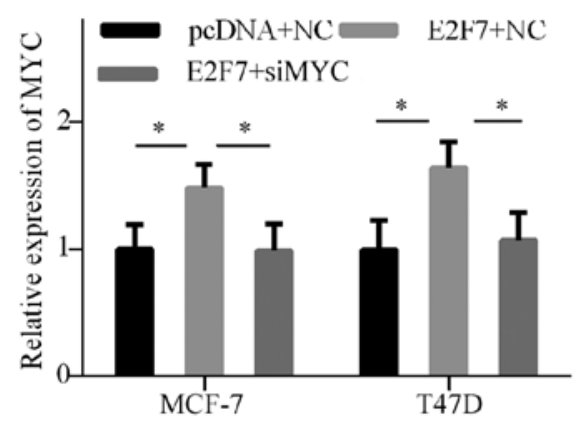

Figure 4. E2F7 inhibits miR-26a expression via MYC upregulation. (A) MCF-7 and T47D cells were transfected with siMYC or NC. MYC knockdown was confirmed by western blotting. (B) miR-26a expression was detected by RT-qPCR. Data are presented as the means \pm standard deviation of three independent experiments. ${ }^{*} \mathrm{P}<0.05$ and ${ }^{* *} \mathrm{P}<0.01$. (C) MCF-7 and T47D cells were transfected with pcDNA3.1 vector plus NC, pcDNA3.1-E2F7 plus NC or pcDNA3.1-E2F7 plus siMYC. MYC expression was detected by western blotting. (D) miR-26a expression levels were analyzed by RT-qPCR. Data are presented as the means \pm standard deviation of three independent experiments. ${ }^{*} \mathrm{P}<0.05$ and ${ }^{* *} \mathrm{P}<0.01$ (one-way analysis of variance followed by least significant difference test). E2F7, E2F transcription factor 7; miR-26a, microRNA 26a; MYC, MYC proto-oncogene, bHLH transcription factor; NC, negative control; RT-qPCR, reverse transcription-quantitative polymerase chain reaction; siMYC, MYC small interfering RNA.

MCF-7 and T47D cells to elevate E2F7 expression (Fig. 3B). Ectopic expression of E2F7 restored MYC gene expression, which was inhibited by miR-26a overexpression (Fig. 3C). These results suggested that miR-26a may indirectly inhibit MYC expression, at least partly via E2F7 repression.

E2F7 overexpression inhibits miR-26a via MYC upregulation. To confirm whether MYC is involved in E2F7-induced miR-26a repression, MYC gene expression was knocked down with siRNA in breast cancer cells (Fig. 4A). As expected, MYC knockdown significantly increased miR-26a expression in MCF-7 and T47D cells (Fig. 4B). To further explore whether E2F7 inhibited miR-26a expression via upregulating MYC expression, E2F7-expressing plasmids and MYC siRNA were cotransfected into MCF-7 and T47D cells. Western blot analysis confirmed that MYC expression was elevated by E2F7 overexpression in both breast cancer cell lines, and decreased by siRNA in E2F7-overexpressing cells (Fig. 4C). RT-qPCR analysis indicated that E2F7 overexpression significantly decreased miR-26a expression, and MYC knockdown abrogated E2F7-induced miR-26a repression (Fig. 4D). These findings suggested that E2F7 overexpression inhibited miR-26a expression via MYC upregulation.

E2F7 knockdown decreases MYC recruitment to the miR-26a promoter. Previously, MYC has been implicated in the regulation of a series of miRNAs, including miR-26a (30). A previous study reported that MYC suppressed miR-26a expression by recruiting EZH2 to the miR-26a promoter (31). To explore the mechanism underlying E2F7-induced miR-26a repression, E2F7 expression was knocked down using siRNA in MCF-7 and T47D cells (Fig. 5A). Subsequently, the promoter regions of CTDSPL (miR-26a1) and CTDSP2 (miR-26a2) were analyzed using the UCSC Genome Browser and two MYC-binding E-box sites were identified (Fig. 5B). Subsequently, ChIP was performed to determine the effects of E2F7 knockdown on MYC enrichment on the miR-26a promoter. The results demonstrated that E2F7 knockdown decreased MYC binding to the miR-26a promoter (Fig. 5C and D). Furthermore, E2F7 knockdown significantly increased miR-26a levels in breast 
A

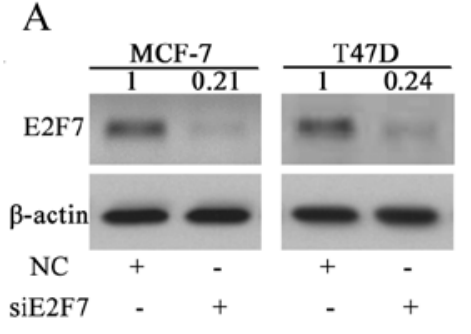

B

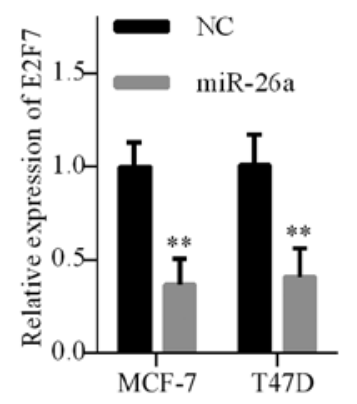

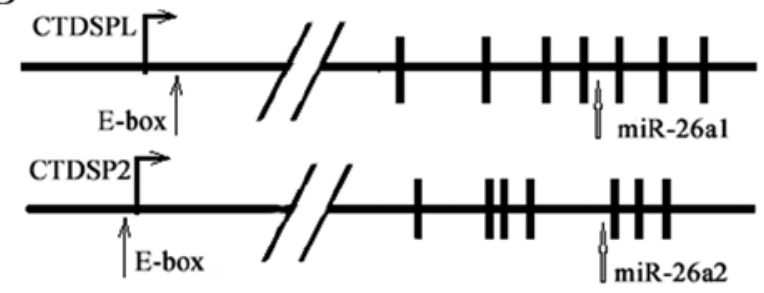

$\mathrm{C}$

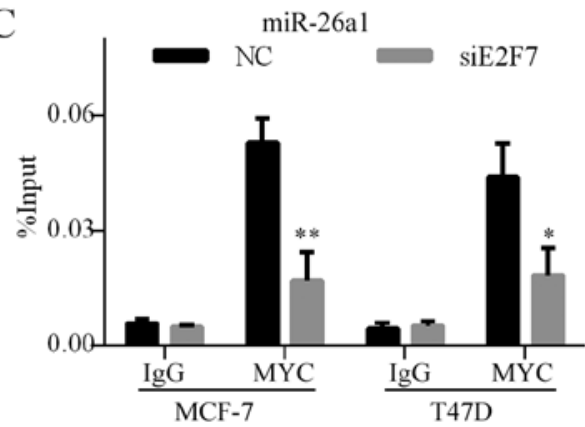

$\mathrm{D}$

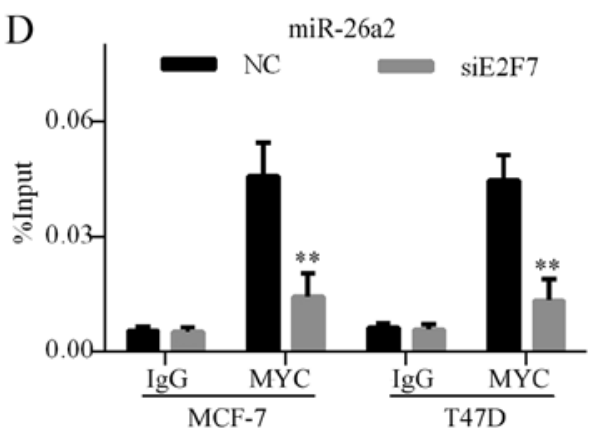

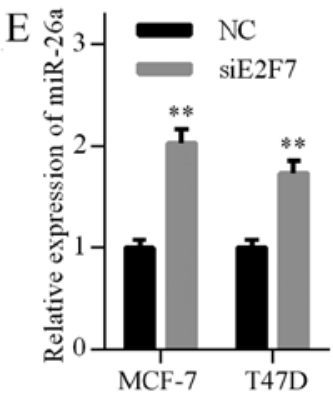

Figure 5. E2F7 knockdown decreases MYC binding to miR-26a gene promoters. (A) E2F7 expression was determined by western blotting in MCF-7 and T47D cells following siE2F7 transfection. (B) Schematic diagram of the MYC binding sites (E-box sequence) in the miR-26a1 (CTDSPL) and miR-26a2 (CTDSP2) promoter regions. (C and D) Enrichment of MYC on miR-26a1 (CTDSPL) and miR-26a2 (CTDSP2) promoters was detected by chromatin immunoprecipitation assay. (E) miR-26a expression was detected by reverse transcription-quantitative polymerase chain reaction in breast cancer cells following E2F7 siRNA transfection. Data are presented as the means \pm standard deviation of three independent experiments. ${ }^{*} \mathrm{P}<0.05$ and ${ }^{* *} \mathrm{P}<0.01$. CTDSP2, CTD small phosphatase 2; CTDSPL, CTD small phosphatase like; E2F7, E2F transcription factor 7; IgG, immunoglobulin G; miR-26a, microRNA 26a; MYC, MYC proto-oncogene, bHLH transcription factor; NC, negative control; siE2F7, E2F7 small interfering RNA.
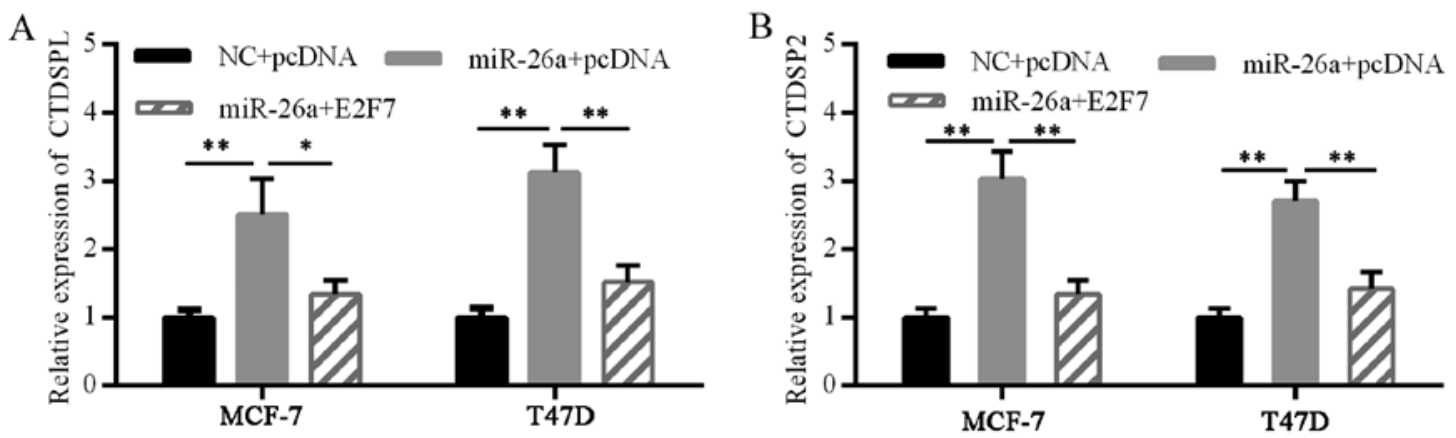

Figure 6. miR-26a and E2F7 form a double-negative feedback loop. MCF-7 and T47D cells were transfected with pcDNA3.1 vector plus NC, pcDNA3.1 vector plus miR-26a mimics or pcDNA3.1-E2F7 plus miR-26a mimics. (A) CTDSPL and (B) CTDSP2 expression was detected by reverse transcription-quantitative polymerase chain reaction. Data are presented as the means \pm standard deviation of three independent experiments. " $\mathrm{P}<0.05$ and ${ }^{* * *} \mathrm{P}<0.01$ (one-way analysis of variance followed by least significant difference test). CTDSP2, CTD small phosphatase 2; CTDSPL, CTD small phosphatase like; E2F7, E2F transcription factor 7; miR-26a, microRNA 26; NC, negative control.

cancer cells (Fig. 5E). These results suggested that E2F7 repression elevated miR-26a expression by inhibiting MYC binding to the miR-26a promoter.

miR-26a and E2F7 form a feedback loop. Concomitant expression of miR-26a with host genes has been identified in physiological and pathological conditions (9). To avoid interference of exogenous miR-26a mimics, CTDSPL and CTDSP2 levels were detected, instead of miR-26a, when conducting a miR-26a self-induction experiment. The miR-26a mimics markedly increased CTDSPL and CTDSP 2 mRNA expression, suggesting a self-perpetuating loop of miR-26a. Furthermore, E2F7 overexpression disturbed this loop (Fig. 6). These results suggested the existence of a double-negative feedback loop of E2F7 and miR-26a in ER-positive breast cancer cells.

miR-26a/E2F7 feedback loop induces TAM resistance in ER-positive breast cancer cells. The present study investigated whether overexpression of miR-26a or knockdown of E2F7 affected proliferation of MCF-7 and T47D cells. A cell viability assay indicated that miR-26a overexpression or E2F7 knockdown inhibited the viability of MCF-7 and T47D cells (Fig. 7A and B).

To further determine the association between miR-26a, E2F7 and TAM resistance, a TAM-resistant breast cancer cell line, MCF-7R, was developed. TAM resistance of MCF-7R 

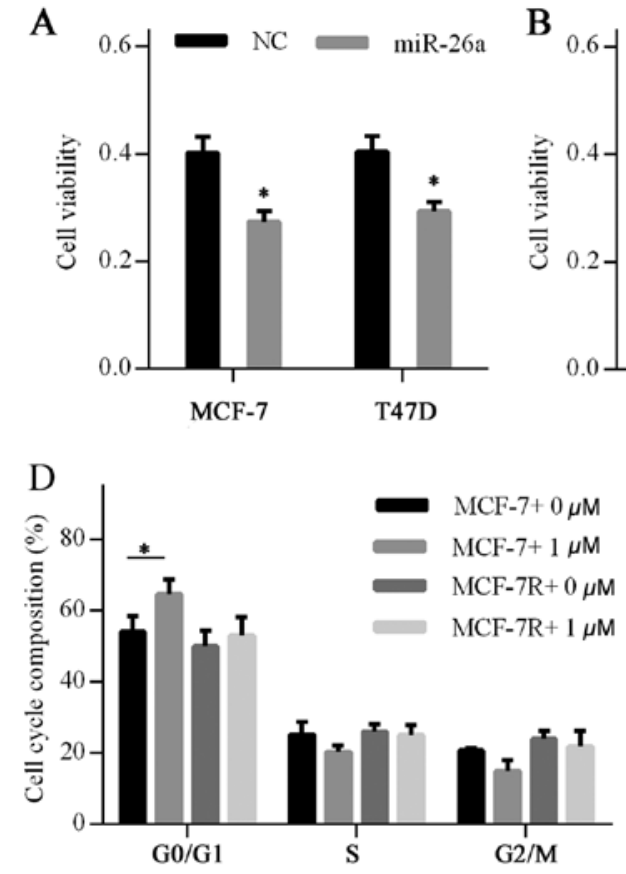

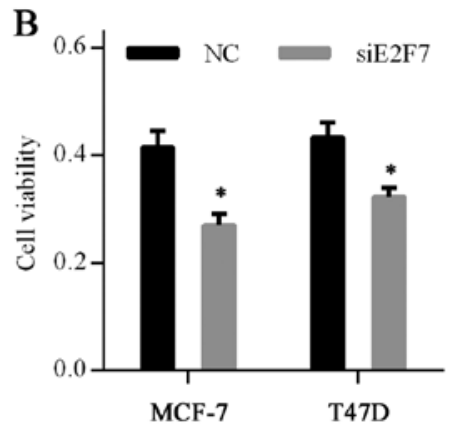

E

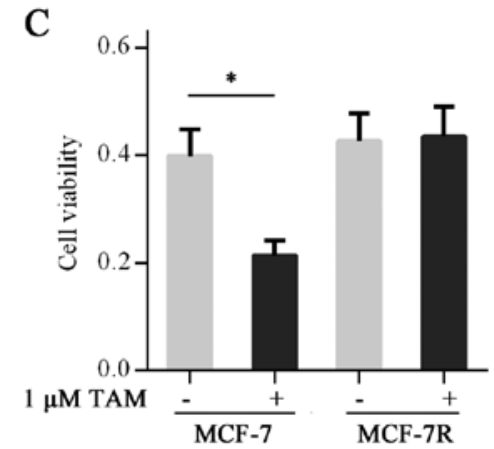

$\mathrm{F}$
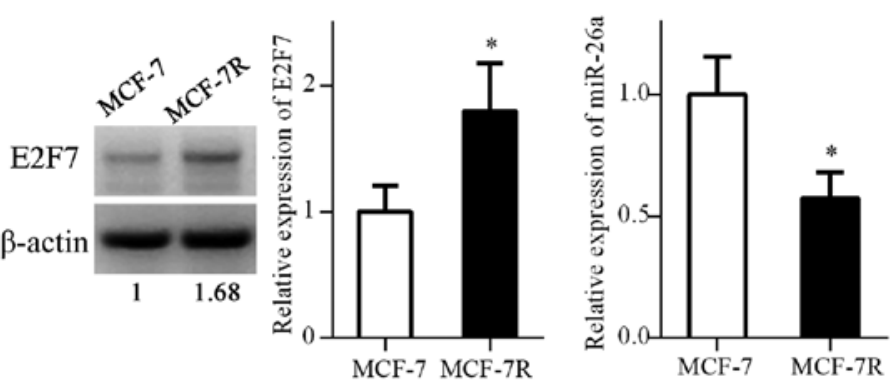

G

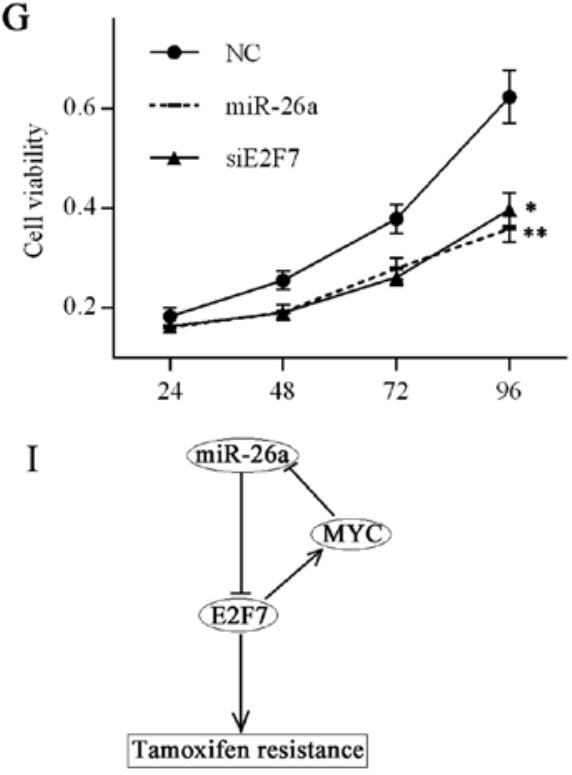

$\mathrm{H} \quad \mathrm{a}$

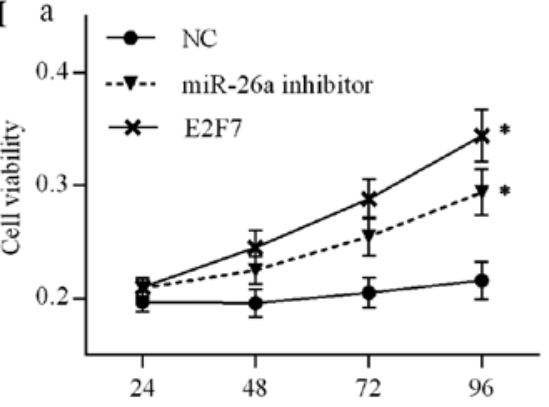

b

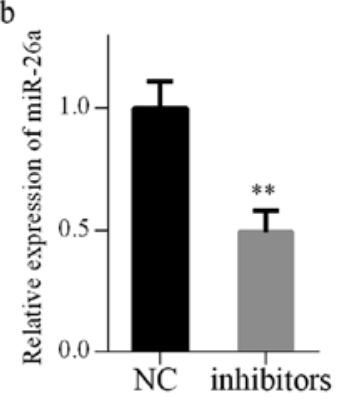

Figure 7. miR-26a/E2F7 feedback loop induces TAM resistance in ER-positive breast cancer. (A) Viability of MCF-7 and T47D cells transfected with miR-26a mimics or NC for $72 \mathrm{~h}$ was detected by MTT assay. (B) Viability of MCF-7 and T47D cells transfected with siE2F7 or NC for 72 h was detected by MTT assay. (C) Viability of MCF-7 and MCF-7R cells treated with $1 \mu \mathrm{M}$ TAM or ethanol for $72 \mathrm{~h}$ was detected by MTT assay. (D) Cell cycle distribution of MCF-7 and MCF-7R cells treated with $1 \mu \mathrm{M}$ TAM or ethanol for $48 \mathrm{~h}$ was analyzed by flow cytometry. ${ }^{*} \mathrm{P}<0.05$ (one-way analysis of variance followed by least significant difference test). (E) E2F7 expression in MCF-7 and MCF-7R cells was detected by western blotting. (F) miR-26a expression in MCF-7 and MCF-7R cells was detected by RT-qPCR. (G) MCF-7R cells were transfected with NC mimics plus siRNA NC, miR-26a mimics plus siRNA NC and siE2F7 plus NC mimics. The viability of MCF-7R cells was detected by MTT assay. (H) MCF-7 cells were transfected with inhibitor NC plus pcDNA3.1 vector, miR-26a inhibitors plus pcDNA3.1 vector and E2F7 vector plus inhibitor NC. (a) Viability of MCF-7 cells was detected by MTT assay. (b) miR-26a knockdown by transfection of MCF-7 cells with inhibitors was confirmed by RT-qPCR. (I) A schematic diagram illustrating the feedback loop of miR-26a and E2F7 in regulating TAM resistance. Data are presented as the means \pm standard deviation of three independent experiments. ${ }^{*} \mathrm{P}<0.05$ and ${ }^{* *} \mathrm{P}<0.01$. E2F7, E2F transcription factor 7; MCF-7R, TAM-resistant MCF-7 cells; miR-26a, microRNA 26a; MYC, MYC proto-oncogene, bHLH transcription factor; NC, negative control; RT-qPCR, reverse transcription-quantitative polymerase chain reaction; siE2F7, E2F7 small interfering RNA; TAM, tamoxifen.

cells was verified by cell viability and cell cycle assays. TAM inhibited cell viability and induced a G1 cell cycle arrest in MCF-7 cells, whereas MCF-7R cells were resistant to the drug (Fig. 7C and D). Subsequently, E2F7 and miR-26a expression were evaluated in MCF-7 cells and MCF-7R cells by western blot analysis and RT-qPCR, respectively. E2F7 expression in
MCF-7R cells was elevated compared with that in MCF-7 cells, whereas miR-26a expression was decreased (Fig. 7E and F).

MCF-7R cells were subsequently transfected with miR-26a mimics, E2F7 siRNA or corresponding controls, and cell viability was monitored by the MTT assay. The results demonstrated that re-expression of miR-26a or knockdown of E2F7 
was capable of resensitizing MCF-7R cells to TAM (Fig. 7G). In addition, MCF-7 cells were transfected with miR-26a inhibitors, E2F7-expressing plasmids or corresponding controls. A cell viability assay indicated that miR-26a knockdown or E2F7 overexpression conferred resistance to TAM in MCF-7 cells (Fig. 7H). The schematic diagram presented in Fig. 7I explains the proposed feedback loop of miR-26a and E2F7 based on the present results.

\section{Discussion}

TAM is highly effective in the treatment of ER-positive breast tumors, which works by inhibiting the ER pathway (3); however, TAM resistance remains a major challenge in the treatment of ER-positive breast cancer. Previous studies have revealed the important roles of miRNAs in the TAM resistance of breast cancer. Re-expression of miR-375, miR-873 and miR-27b has been reported to reverse TAM resistance, whereas miR-221/222 upregulation confers TAM resistance (23,32-34). The present study reported that miR-26a expression was inhibited in ER-positive breast cancer, whereas E2F7 expression was elevated. Subsequently, the results demonstrated that a miR-26a/E2F7 feedback loop resulted in miR-26a downregulation and E2F7 overexpression, and thereby contributed to TAM resistance in ER-positive breast cancer cells.

miR-26a is differently expressed in cancer tissues and exhibits diverse functions dependent on cancer type. miR-26a expression is reduced in gastric cancer, hepatocellular carcinoma and gallbladder cancer compared with in normal adjacent tissue (35-37). Conversely, miR-26a expression is elevated in lung cancer, glioma and ovarian cancer (38-40). The present study revealed that miR-26a expression was reduced in ER-positive breast cancer, whereas E2F7 expression was elevated, as previously described $(10,41)$. miR-26a and E2F7 expression levels were detected by RT-qPCR analysis of clinical specimens, and findings were confirmed using TCGA datasets. Furthermore, an inverse correlation between miR-26a and E2F7 expression was identified in ER-positive breast cancer tissues, suggesting a possible crosstalk between the two molecules.

A previous study demonstrated that $\mathrm{E} 2 \mathrm{~F} 7$ is a direct target of miR-26a in AML cells (29). miRNAs repress target gene expression through modulation of translation efficiency or degradation of mRNAs (5). The present study revealed that ectopic expression of miR-26a markedly decreased E2F7 protein, but not mRNA, expression. These results indicated that miR-26a may directly inhibit E2F7 via translational inhibition. Notably, miR-26a overexpression also led to MYC repression in breast cancer cells. A previous study reported that ectopic miR-26a expression inhibits MYC expression in aggressive B-cell lymphomas (42); however, the underlying mechanism remains unknown. Furthermore, E2F7 silencing increases expression of the miR-17-92 cluster by inhibiting MYC transcriptional activity in AML cells (29). In addition, E2F7 has been revealed to increase MYC expression by decreasing E2F1/2/3 recruitment to the MYC gene promoter region (43). In the present study, it was demonstrated that ectopic expression of E2F7 abrogated miR-26a-induced MYC repression. These results suggested that miR-26a overexpression may inhibit MYC expression by repressing E2F7 in breast cancer cells.
It has been reported that E2F7 inhibits the activity of other E2F family members, including E2F1, E2F2 and E2F3 $(15,18,43)$. E2F7 knockdown elevates miR-26a expression by increasing the recruitment of E2F3 to the miR-26a promoter (43). A recent study demonstrated that MYC represses miR-26a expression by recruiting EZH2 to the gene promoter (31). The present study aimed to determine whether E2F7 regulated miR-26a expression by modulating recruitment of MYC to the miR-26a promoter. The results demonstrated that ectopic expression of E2F7 inhibited miR-26a expression, at least partly by increasing MYC expression. Furthermore, E2F7 knockdown significantly reduced the recruitment of MYC to the miR-26a gene promoter and led to miR-26a re-expression.

The present study revealed that miR-26a mimics increased the expression of the miR-26a host genes, CTDSPL and CTDSP2, whereas E2F7 overexpression abrogated miR26a-induced CTDSPL and CTDSP2 expression. These findings indicated that miR-26a and E2F7 formed a feedback loop in ER-positive breast cancer. During breast carcinogenesis, the balance of the feedback loop may be disrupted and result in miR-26a suppression and E2F7 overexpression. In the present study, downregulation of miR-26a and upregulation of E2F7 were also detected in TAM-resistant cells. A previous study reported that $\mathrm{E} 2 \mathrm{~F} 7$ overexpression led to TAM resistance by suppressing the miR-15a/16 cluster in breast cancer cells (38). Furthermore, not only E2F7 overexpression, but also miR-26a knockdown, conferred resistance to TAM in MCF-7 cells. Conversely, miR-26a overexpression and E2F7 silencing resensitized MCF-7R cells to TAM.

In conclusion, the present study demonstrated that crucial functional crosstalk may exist between miR-26a and E2F7 via a double-negative feedback loop in ER-positive breast cancer, which may have an important role in TAM resistance. Therefore, it may be hypothesized that re-expression of miR-26a or inhibition of E2F7 are potential therapeutic approaches for the treatment of TAM-resistant breast cancer in the future.

\section{Acknowledgements}

Not applicable.

\section{Funding}

The present study was supported by the National Natural Science Foundation of China (grant no. 81272418; Hong Ren), the National Science Foundation for Young Scientists of China (grant no. 81602597; Xin Sun) and the National Science Foundation for Young Scientists of China (grant no. 81402506; Sida Qin).

\section{Availability of data and materials}

The datasets used and/or analyzed during the current study are available from the corresponding author on reasonable request.

\section{Authors' contributions}

YP, HR and JL designed the study. JL, XL, MW, GX and GY performed the experiments. XL, MW, GX and YL contributed 
to data acquisition and analysis. JL, XL and YP wrote the manuscript. HW, YL and XS collected the clinical samples and contributed to clinical data analysis. GX, YL and XS contributed to bioinformatics analysis. SQ and ND contributed to statistical analysis and revised the manuscript critically for important intellectual content. XS, SQ and ND were involved in drafting the manuscript. All authors have read and approved the final manuscript.

\section{Ethics approval and consent to participate}

The present study was approved by the Ethics Committee of $\mathrm{Xi}^{\prime}$ an Jiaotong University First Affiliated Hospital and each patient provided written informed consent.

\section{Patient consent for publication}

Not applicable.

\section{Competing interest}

The authors declare that they have no competing interests.

\section{References}

1. Siegel RL, Miller KD and Jemal A: Cancer statistics, 2016. CA Cancer J Clin 66: 7-30, 2016.

2. Vargo-Gogola T and Rosen JM: Modelling breast cancer: One size does not fit all. Nat Rev Cancer 7: 659-672, 2007.

3. Mandlekar S and Kong AN: Mechanisms of tamoxifen-induced apoptosis. Apoptosis 6: 469-477, 2001.

4. Qadir MA, Kwok B, Dragowska WH, To KH, Le D, Bally MB and Gorski SM: Macroautophagy inhibition sensitizes tamoxifen-resistant breast cancer cells and enhances mitochondrial depolarization. Breast Cancer Res Treat 112: 389-403, 2008.

5. Bartel DP: MicroRNAs: Genomics, biogenesis, mechanism, and function. Cell 116: 281-297, 2004

6. Sun X, Jiao X, Pestell TG, Fan C, Qin S, Mirabelli E, Ren H and Pestell RG: MicroRNAs and cancer stem cells: The sword and the shield. Oncogene 33: 4967-4977, 2014.

7. Di Leva G, Garofalo M and Croce CM: MicroRNAs in cancer. Annu Rev Pathol 9: 287-314, 2014.

8. Fatica A and Fazi F: MicroRNA-regulated pathways in hematological malignancies: How to avoid cells playing out of tune. Int J Mol Sci 14: 20930-20953, 2013.

9. Zhu Y, Lu Y, Zhang Q, Liu JJ, Li TJ, Yang JR, Zeng C and Zhuang SM: MicroRNA-26a/b and their host genes cooperate to inhibit the G1/S transition by activating the $\mathrm{pRb}$ protein. Nucleic Acids Res 40: 4615-4625, 2012.

10. Zhang B, Liu XX, He JR, Zhou CX, Guo M, He M, Li MF, Chen GQ and Zhao Q: Pathologically decreased miR-26a antagonizes apoptosis and facilitates carcinogenesis by targeting MTDH and EZH2 in breast cancer. Carcinogenesis 32: 2-9, 2011.

11. Liu P, Tang H, Chen B, He Z, Deng M, Wu M, Liu X, Yang L, Ye F and Xie X: miR-26a suppresses tumour proliferation and metastasis by targeting metadherin in triple negative breast cancer. Cancer Lett 357: 384-392, 2015.

12. Jansen MPHM, Reijm EA, Sieuwerts AM, Ruigrok-Ritstier K, Look MP, Rodríguez-González FG, Heine AA, Martens JW, Sleijfer S, Foekens JA, et al: High miR-26a and low CDC2 levels associate with decreased EZH2 expression and with favorable outcome on tamoxifen in metastatic breast cancer. Breast Cancer Res Treat 133: 937-947, 2012.

13. Joshi T, Elias D, Stenvang J, Alves CL, Teng F, Lyng MB, Lykkesfeldt AE, Brünner N, Wang J, Gupta R, et al: Integrative analysis of miRNA and gene expression reveals regulatory networks in tamoxifen-resistant breast cancer. Oncotarget 7 : 57239-57253, 2016.

14. DeGregori J and Johnson DG: Distinct and overlapping roles for E2F family members in transcription, proliferation and apoptosis. Curr Mol Med 6: 739-748, 2006.
15. Logan N, Delavaine L, Graham A, Reilly C, Wilson J, Brummelkamp TR, Hijmans EM, Bernards $R$ and La Thangue NB: E2F-7: A distinctive E2F family member with an unusual organization of DNA-binding domains. Oncogene 23: 5138-5150, 2004

16. Endo-Munoz L, Dahler A, Teakle N, Rickwood D, HazarRethinam M, Abdul-Jabbar I, Sommerville S, Dickinson I, Kaur P, Paquet-Fifield S, et al: E2F7 can regulate proliferation, differentiation, and apoptotic responses in human keratinocytes: Implications for cutaneous squamous cell carcinoma formation. Cancer Res 69: 1800-1808, 2009.

17. Di Stefano L, Jensen MR and Helin K: E2F7, a novel E2F featuring DP-independent repression of a subset of E2F-regulated genes. EMBO J 22: 6289-6298, 2003.

18. Zalmas LP, Zhao X, Graham AL, Fisher R, Reilly C, Coutts AS and La Thangue NB: DNA-damage response control of E2F7 and E2F8. EMBO Rep 9: 252-259, 2008.

19. Li Q, Qiu XM, Li QH, Wang XY, Li L, Xu M, Dong M and Xiao YB: MicroRNA-424 may function as a tumor suppressor in endometrial carcinoma cells by targeting E2F7. Oncol Rep 33: 2354-2360, 2015.

20. Reimer D, Sadr S, Wiedemair A, Stadlmann S, Concin N, Hofstetter G, Müller-Holzner E, Marth C and Zeimet AG: Clinical relevance of E2F family members in ovarian cancer - an evaluation in a training set of 77 patients. Clin Cancer Res 13: 144-151, 2007.

21. Hazar-Rethinam M, de Long LM, Gannon OM, Topkas E, Boros S, Vargas AC, Dzienis M, Mukhopadhyay P, Simpson F, Endo-Munoz L, et al: A novel E2F/sphingosine kinase 1 axis regulates anthracycline response in squamous cell carcinoma. Clin Cancer Res 21: 417-427, 2015.

22. Thrane S, Lykkesfeldt AE, Larsen MS, Sorensen BS and Yde CW: Estrogen receptor $\alpha$ is the major driving factor for growth in tamoxifen-resistant breast cancer and supported by HER/ERK signaling. Breast Cancer Res Treat 139: 71-80, 2013.

23. Cui J, Yang Y, Li H, Leng Y, Qian K, Huang Q, Zhang C, Lu Z, Chen J, Sun T, et al: MiR-873 regulates ER $\alpha$ transcriptional activity and tamoxifen resistance via targeting CDK3 in breast cancer cells. Oncogene 34: 3895-3907, 2015.

24. Goldhirsch A, Ingle JN, Gelber RD, Coates AS, Thürlimann B and Senn HJ; Panel members: Thresholds for therapies: Highlights of the St Gallen International Expert Consensus on the primary therapy of early breast cancer 2009. Ann Oncol 20: 1319-1329, 2009

25. Pang Y, Liu J, Li X, Zhang Y, Zhang B, Zhang J, Du N, Xu C, Liang R, Ren H, et al: Nano Let $7 \mathrm{~b}$ sensitization of eliminating esophageal cancer stem like cells is dependent on blockade of Wnt activation of symmetric division. Int J Oncol 51: 1077-1088, 2017.

26. Livak KJ and Schmittgen TD: Analysis of relative gene expression data using real-time quantitative PCR and the 2(-DeltaDeltaC(T)) method. Methods 25: 402-408, 2001.

27. Lim YY, Wright JA, Attema JL, Gregory PA, Bert AG, Smith E, Thomas D, Lopez AF, Drew PA, Khew-Goodall Y, et al: Epigenetic modulation of the miR-200 family is associated with transition to a breast cancer stem-cell-like state. J Cell Sci 126: 2256-2266, 2013.

28. Licchesi JD, Van Neste L, Tiwari VK, Cope L, Lin X, Baylin SB and Herman JG: Transcriptional regulation of Wnt inhibitory factor-1 by Miz-1/c-Myc. Oncogene 29: 5923-5934, 2010.

29. Salvatori B, Iosue I, Mangiavacchi A, Loddo G, Padula F, Chiaretti S, Peragine N, Bozzoni I, Fazi F and Fatica A: The microRNA-26a target E2F7 sustains cell proliferation and inhibits monocytic differentiation of acute myeloid leukemia cells. Cell Death Dis 3: e413, 2012

30. Tao J, Zhao X and Tao J: c-MYC-miRNA circuitry: A central regulator of aggressive B-cell malignancies. Cell Cycle 13: 191-198, 2014.

31. Zhao X, Lwin T, Zhang X, Huang A, Wang J, Marquez VE, Chen-Kiang S, Dalton WS, Sotomayor E and Tao J: Disruption of the MYC-miRNA-EZH2 loop to suppress aggressive B-cell lymphoma survival and clonogenicity. Leukemia 27: 2341-2350, 2013.

32. Ward A, Balwierz A, Zhang JD, Küblbeck M,Pawitan Y,HielscherT, Wiemann S and Sahin Ö: Re-expression of microRNA-375 reverses both tamoxifen resistance and accompanying EMT-like properties in breast cancer. Oncogene 32: 1173-1182, 2013.

33. Zhu J, Zou Z, Nie P, Kou X, Wu B, Wang S, Song Z and He J: Downregulation of microRNA-27b-3p enhances tamoxifen resistance in breast cancer by increasing NR5A2 and CREB1 expression. Cell Death Dis 7: e2454, 2016. 
34. Miller TE, Ghoshal K, Ramaswamy B, Roy S, Datta J, Shapiro CL, Jacob S and Majumder S: MicroRNA-221/222 confers tamoxifen resistance in breast cancer by targeting p27Kip1. J Biol Chem 283: 29897-29903, 2008.

35. Deng M, Tang HL, Lu XH, Liu MY, Lu XM, Gu YX, Liu JF and He ZM: miR-26a suppresses tumor growth and metastasis by targeting FGF9 in gastric cancer. PLoS One 8: e72662, 2013.

36. Yang X, Liang L, Zhang XF, Jia HL, Qin Y, Zhu XC, Gao XM, Qiao P, Zheng Y, Sheng YY, et al: MicroRNA-26a suppresses tumor growth and metastasis of human hepatocellular carcinoma by targeting interleukin-6-Stat3 pathway. Hepatology 58: $158-170,2013$

37. Zhou H, Guo W, Zhao Y, Wang Y, Zha R, Ding J, Liang L, Hu J, Shen H, Chen Z, et al: MicroRNA-26a acts as a tumor suppressor inhibiting gallbladder cancer cell proliferation by directly targeting HMGA2. Int J Oncol 44: 2050-2058, 2014.

38. Lin G, Liu B, Meng Z, Liu Y, Li X, Wu X, Zhou Q and Xu K: MiR-26a enhances invasive capacity by suppressing GSK3 $\beta$ in human lung cancer cells. Exp Cell Res 352: 364-374, 2017.

39. Qian X, Zhao P, Li W, Shi ZM, Wang L, Xu Q, Wang M, Liu N, Liu LZ and Jiang BH: MicroRNA-26a promotes tumor growth and angiogenesis in glioma by directly targeting prohibitin. CNS Neurosci Ther 19: 804-812, 2013.
40. Shen W, Song M, Liu J, Qiu G, Li T, Hu Y and Liu H: MiR-26a promotes ovarian cancer proliferation and tumorigenesis. PLoS One 9: e86871, 2014

41. Chu J, Zhu Y, Liu Y, Sun L, Lv X, Wu Y, Hu P, Su F, Gong C, Song E, et al: E2F7 overexpression leads to tamoxifen resistance in breast cancer cells by competing with E2F1 at miR-15a/16 promoter. Oncotarget 6: 31944-31957, 2015.

42. Zhang X, Zhao X, Fiskus W, Lin J, Lwin T, Rao R, Zhang Y, Chan JC, Fu K, Marquez VE, et al: Coordinated silencing of MYC-mediated miR-29 by HDAC3 and EZH2 as a therapeutic target of histone modification in aggressive B-Cell lymphomas. Cancer Cell 22: 506-523, 2012.

43. Mitxelena J, Apraiz A, Vallejo-Rodríguez J, Malumbres M and Zubiaga AM: E2F7 regulates transcription and maturation of multiple microRNAs to restrain cell proliferation. Nucleic Acids Res 44: 5557-5570, 2016. 